\title{
Research on University Online Welcome and Enrollment Education of Prospective College Students
}

\author{
Junpeng Huang ${ }^{1}$ \\ ${ }^{1}$ Wuhan Textile University, Wuhan, Hubei, 430000 \\ 346591653@163.com
}

KEYWORDS: Online Orientation; Prospective College Students; School Education

\begin{abstract}
From origin and development of Chinese Universities online welcome, this paper introduced online welcome from the initial single-platform network systems, to today's micro-blogging, micro letter, QQ group, BBS forum, orientation network systems, orientation site, Baidu Post Bar and other species carrier. Online college online welcome provides an important platform for the "home-school interaction" teacher-student interaction and provided an important way to the pre-new year, and from the effectiveness and side effects in the form of content is more prominent distinctive, arousing students enthusiasm. Through online universities welcome, the former "prospective college students' enrollment provides a form of lively, multi-faceted content-rich educational content such as school history school love, life safety, discipline rules and regulations, professional learning, political thought and so on.
\end{abstract}

\section{Introduction}

After the popularization of higher education, expanding enrollment in colleges and universities, community and family to look forward to increasing the value of higher education, pluralistic society needs, market demand, welcome to work for a higher challenge. Universities welcome the work alone to solve a small part of the original student Yi Shizhu issues, converted to each university to solve the thousands or even tens of thousands of newborn need to learn other aspects of the daily life issues every year. Incomplete, a freshman report to relate to academic departments, work department door, admissions department, logistics dorm, catering services, household services, financial sector, to defend the armed services, medical department and other departments. In order to improve the efficiency of orientation, as well as the popularity of new media, network orientation provides a convenient channel for college orientation work.

Tsinghua University in 2001 began construction of the first online orientation system, which greatly improves the efficiency of orientation by parents and "prospective college students' praise. With the development of digital information, online orientation work to enter the multi-channel, multi-tools, personalized service stage. Orientation currently online work mainly relying on microblogging, micro letter, QQ group, BBS forum, orientation network systems, orientation site, Baidu Post Bar and other carriers to solve various problems, "prospective college students' academic and life. Universities welcome the work has entered the information platform stage, the progress of science and technology, the emergence and spread of new media, the Internet has become increasingly mature orientation and humane. 


\section{Significance and Practical Effect of Online Universities Welcome}

Compared with the traditional ways and means of orientation, orientation online universities work with a platform open, spread rapidly, exchange equality, free from the constraints of time, the carrier diversity, higher efficiency and so on, which is the pursuit of individuality, like to explore new things 90 speaking students, it is easier to accept and use, greatly enhanced the effectiveness of work orientation.

(A) Online Welcome to the pre-school education provides an important platform;

Online Universities welcome the New Year not only improve efficiency, but also in school education, to enable students to school as soon as the relevant circumstances and in contact with teachers and students, the freshmen education provides an important platform, illustrated, lively improve the freshmen education The timeliness.

(B) Online Welcome to "home-school interaction" teacher-student interaction and provide an important way;

Online orientation system openness, so that the community, families and students themselves are more comprehensive, efficient and learned all aspects of the school; at the same time, through the orientation system for home-school interaction and teacher-student interaction provides a communication platform.

(C) Timeliness and form of online content orientation more clearly highlight, to mobilize the enthusiasm of students to participate.

Network information communicated more efficient, while the network communication platform widely welcome, such as microblogging, micro letter, QQ group, BBS forum, orientation network systems, orientation site, Baidu Post Bar and other platforms carrier for efficient, vivid, diverse complete the online orientation facilitated.

\section{Educational Content of Universities Online Welcome}

(A) School situation school history education.

As the first-line student workers from participating in the three years of continuous online experience, we welcome students to school history school situation relatively high degree of interest. Mainly in schools in the ranking, school location, school environment, school history, culture, accommodation and other colleges and universities nationwide. Online orientation process, the school situation school history education in schools, use of the school for students to have a "first effect", if the situation of education in terms of school history school is not in place, and even lead to the students leave school repetition; on the contrary, if properly guidance and education, and even make college exam was due to the non-favorite school admission "quasi-students", quickly accepted good school.

(B) Life safety education.

Faced with an increasingly developed society, because the interests induce criminals will take advantage of the weakness of newborn gullible, drivers extortion, even against their lives and property. For "quasi-students" in terms of life safety education is to remind students to pay attention to personal and financial security. The media exposures the disappearance of five college students that been violated and personal events. As "prospective college students' social undesirables will use its compassion, enthusiasm and other psychological crime, so they should strengthen their life and safety education and improve vigilance. 
(C) School discipline school rules education.

Discipline rules and regulations are an important part of education freshmen. But as a "quasi-students" can welcome website, school website, and share files and other forms of group to advance understanding of the relevant rules and regulations of the school. Help guide students to advance into the university roles and define the rights, responsibilities and obligations of university students, specifically what things you can do things that are illegal activities which provide an important basis for the good college students' career planning.

(D) Professional learning education

Professional learning education is generally divided into three cases. First, apply the professional and admitted. Although these students have some understanding of the professional admission, but for a professional future employment prospects, postgraduate and professional disciplines ranking prospects limited understanding, through the online orientation process, to further strengthen their professional convictions. Second, apply for transfers to other professional but was admitted to the existing professional. Such students may be more inclined to apply for professional original, little is known about the admissions professional, and even have the idea of regulating professional. Such students are admitted on the one hand to strengthen the professional presentation for education; on the other hand can introduce the school to turn professional and minor related policies, double degree policy, so that students do understand the multi-channels and further detailed experience and after enrollment After understanding, make a choice. Third, mainly for professional employment prospects and postgraduate circumstances question.

(E) Political and ideological education.

For "quasi-students", the ability to enter institutions of higher learning, have a very high political enthusiasm and passion for learning. Most have a particularly positive move closer to the party closer enthusiasm. Online orientation advance party can introduce the basic theory of knowledge, as well as colleges and universities to learn lessons caucus circumstances according to the school opened.

\section{REFERENCE:}

[1] Wei Yantao, University Enrollment Education Reflections [J]. Science \& Education, 2013 (01).

[2] Zhang Yuhong. Freshmen Education Status and Countermeasures [J]. Managers, 2013 (09).

[3] Wang Haidong. "90" New Thinking Freshmen Education [J]. Industry and Technology Forum, 2013 (14).

[4] Chen Lirong. Network College Freshmen Education Innovation-A Case Study of Hunan Normal University Online Orientation [J]. Zunyi Normal College, 2012 (02).

[5] Yang Chunrong. University Digital Orientation Status Quo [J]. Computer Knowledge and Technology, 2012 (08).

[6] Liu Junyan. Freshmen Education in Colleges and Universities [J]. Reform and Opening Up, 2010 (18). 